\title{
Author Correction: Early-career reflections: Get the balance right
}

Leah Stokes (1)

Correction to: Nature Energy https://doi.org/10.1038/s41560-020-00742-0, published online 21 January 2021.

In the version of this Viewpoint article originally published, in the sentence that begins "I feel a personal responsibility...", the phrase "publish for bolder climate policy" should have been "push for bolder climate policy". This has now been corrected in all versions.

Published online: 1 February 2021

https://doi.org/10.1038/s41560-021-00785-x

(C) Springer Nature Limited 2021 